\title{
BOTH BLOOD AND CRYSTALLOID-BASED EXTRACELLULAR SOLUTIONS ARE SUPERIOR TO INTRACELLULAR SOLUTIONS FOR LUNG PRESERVATION
}

Oliver A. R. Binns, MD

Nuno F. DeLima, MD

Scott A. Buchanan, MD

Jeffrey T. Cope, MD

Robert C. King, MD

Chris A. Marek, BS

Kimberly S. Shockey, MS

Curtis G. Tribble, MD, FACS

Irving L. Kron, MD, FACS
Objective: Lung transplantation remains limited by donor organ ischemic time, inadequate graft preservation, and reperfusion injury. We evaluated lung preservation with use of an extracellular solution, with or without the addition of blood, as compared with preservation with the intracellular Euro-Collins solution. Methods: With use of an isolated, whole blood perfused/ventilated rabbit lung model, we studied three groups of animals. Lungs were flushed with Euro-Collins, low-potassium dextran, or $20 \%$ blood-low-potassium dextran solution. Lungs were harvested en bloc, stored inflated at $4^{\circ} \mathrm{C}$ for 18 hours, and then reperfused at $60 \mathrm{ml} / \mathrm{min}$ with whole blood. Continuous measurements of pulmonary artery pressure, pulmonary vascular resistance, and dynamic airway compliance were obtained. Fresh, nonrecirculated venous blood was used to determine the single-pass pulmonary venous-arterial oxygen gradient. Results: Lungs preserved with Euro-Collins solution demonstrated elevated pulmonary artery pressure and pulmonary vascular resistance when compared with those preserved with low-potassium dextran and $20 \%$ blood-lowpotassium dextran solutions (pulmonary artery pressure: $40.8 \pm 2.2 \mathrm{~mm}$ $\mathrm{Hg}$ vs $28.9 \pm 2.4 \mathrm{~mm} \mathrm{Hg}$ and $28.3 \pm 1.5 \mathrm{~mm} \mathrm{Hg}$, respectively, $p<0.001$; pulmonary vascular resistance: $46.0 \pm 3.1 \times 10^{3}$ dynes $\cdot \mathrm{sec} \cdot \mathrm{cm}^{-5} \mathrm{vs}$ $29.0 \pm 4.2 \times 10^{3}$ dynes $\cdot \mathrm{sec} \cdot \mathrm{cm}^{-5}$ and $28.8 \pm 2.3 \times 10^{3}$ dynes $\cdot \sec \cdot \mathrm{cm}^{-5}$, respectively, $p<0.001$ ). Euro-Collins solution-preserved lungs demonstrated a significant drop in compliance when compared with those preserved with low-potassium dextran and $20 \%$ blood-low-potassium dex$\operatorname{tran}(-21.9 \% \pm 4.7 \%$ vs $1.8 \% \pm 3.3 \%$ and $1.4 \% \pm 6.2 \%$, respectively; $p=$ 0.002). Oxygenation was improved with low-potassium dextran and $20 \%$ blood-low-potassium dextran solutions as compared with that with EuroCollins solution $(296.3 \pm 54.6 \mathrm{~mm} \mathrm{Hg}$ and $290.2 \pm 66.4 \mathrm{~mm} \mathrm{Hg}$, respectively, vs $37.2 \pm 4.6 \mathrm{~mm} \mathrm{Hg} p=0.001$ ). Conclusions: Extracellular solutions provided superior preservation of pulmonary function in this rabbit lung model of ischemia-reperfusion. However, the addition of blood does not confer any demonstrable advantage over low-potassium dextran solution alone with use of an 18-hour period of cold ischemia. ( $J$ Thorac Cardiovasc Surg 1996;112:1515-21)
From the Division of Thoracic and Cardiovascular Surgery, Department of Surgery, University of Virginia Health Sciences Center, Charlottesville, Va.

Supported by the National Institutes of Health under RO1 grant No. HL 48242 and National Research Service Award fellowship No. F32HL09115-01A1. Additional support from CNPqConselho Nacional de Desenvolvimento Cientifico e Tecnologico, Brazil.

Read at the Seventy-sixth Annual Meeting of the American Association for Thoracic Surgery, San Diego, Calif., April 28-May 1, 1996.
Received for publication May 6, 1996; revisions requested June 24, 1996; revisions received July 22, 1966; accepted for publication July 25, 1996.

Address for reprints: Irving L. Kron, MD, Division of Thoracic and Cardiovascular Surgery, Department of Surgery, Box 310, University of Virginia Health Sciences Center, Charlottesville, VA 22908.

Copyright (C) 1996 by Mosby-Year Book, Inc.

$0022-5223 / 96 \$ 5.00+0 \quad \mathbf{1 2 / 6 / 7 6 8 2 2}$ 
$T^{\mathrm{t}}$ he current success of clinical lung transplantation relies on limited cold ischemic periods and adequate graft preservation. Despite advances in lung preservation, reperfusion injury continues to be an unpredictable and often devastating occurrence. Numerous investigations have identified methods of preventing or ameliorating the effects of reperfusion injury. ${ }^{1-4}$ However, ischemia-reperfusion injury of the lung continues to be in part attributable to inadequate graft preservation. The most commonly used method of lung preservation is hypothermic single-flush perfusion of the pulmonary vasculature..$^{5}$ This technique allows rapid cooling of the graft and distribution of a preservation solution throughout the lung. Acceptable results with singleflush perfusion have been attained, although the optimal preservation solution to accompany this technique remains undetermined.

Theoretic advantages for the use of either extracellular or intracellular types of preservation solutions exist, and the controversy over which type of solution provides optimal protection of the lung continues. Low-potassium extracellular-type solutions have been used both clinically and in experimental models and demonstrate the potential for improved lung function and prolonged storage. ${ }^{6-12}$ Other authors have also reported excellent results with the use of intracellular-type solutions, ${ }^{13-15}$ of which Euro-Collins solution is most commonly used. The potential benefits of blood-based preservation solutions have also been described. ${ }^{16-18}$

We have previously reported that the use of extracellular-type preservation solutions in the setting of high-flow reperfusion results in improved lung function ${ }^{19}$ and that the intracellular-type EuroCollins solution exacerbates lung injury. ${ }^{20}$ Given these findings, in the current study we hypothesized that extracellular-type preservation solutions would provide superior lung function as compared with results using the standard intracellular-type solution, Euro-Collins solution, after an extended 18hour period of cold ischemia. Because of its efficacy in cardiac protection, the potential benefit of using a blood-based solution was also investigated in an isolated blood-perfused/ventilated rabbit lung model.

\section{Material and methods}

Lung-heart block harvesting. In the following experimental model, previously described by our laboratory, ${ }^{19}$ 23 adult New Zealand White rabbits of either sex (3.0 to $3.5 \mathrm{~kg}$ ) were randomized to three experimental groups.
Each rabbit was anesthetized with intramuscular ketamine $(50 \mathrm{mg} / \mathrm{kg})$ and xylazine $(5 \mathrm{mg} / \mathrm{kg})$. Tracheal intubation was done via a tracheostomy and followed by paralysis with metocurine $(0.2 \mathrm{mg} / \mathrm{kg}$ intravenously). Mechanical ventilation of the lung was instituted (ventilator No. RSP1002, Kent Scientific Corporation, Litchfield, Conn.) with room air with a tidal volume of $12 \mathrm{ml} / \mathrm{kg}$ and a rate of 20 breaths/min.

A median sternotomy and thymectomy were then done. The superior and inferior venae cavae were loosely encircled with ligatures and the pericardium opened. Both the pulmonary artery and aorta were dissected free and similarly encircled. A purse-string suture was then placed in the free wall of the right ventricle and the rabbit was heparinized ( $500 \mathrm{U} / \mathrm{kg}$ intravenously). After injection of $30 \mu \mathrm{g}$ of prostaglandin $\mathrm{E}_{1}\left(\mathrm{PGE}_{1}\right.$ : Alprostadil, Upjohn Company, Kalamazoo, Mich.) directly into the pulmonary artery, the venae cavae were ligated, thus initiating the 18-hour ischemic period.

The pulmonary artery was then cannulated through a right ventriculotomy in the center of the purse-string and both the right ventricle and pulmonary artery ligatures were tied around the cannula. After the left ventricle was vented through a left ventriculotomy and the aorta ligated, $50 \mathrm{ml} / \mathrm{kg}$ of the preservation solution to be evaluated as per the protocol was infused into the pulmonary artery from a height of $30 \mathrm{~cm}$ and at $4^{\circ} \mathrm{C}$. Topical cooling was achieved with cold saline slush. During the pulmonary artery flush, the left atrium was cannulated through the left ventriculotomy and a second purse-string suture tied around the cannula. A second catheter was placed in the left atrium to directly transduce left atrial pressures. After the pulmonary artery flush, the inflow and outflow cannulas were clamped. Care was taken to leave the pleurae intact until the completion of the flush to avoid parenchymal injury. The lungs were stored inflated by clamping the tracheal tube at end inspiration. The lung-heart block was then excised, immersed in cold $0.9 \%$ saline solution, and stored at $4^{\circ} \mathrm{C}$ for 18 hours.

All experimental protocols were reviewed and approved by an institutional animal use committee. All animals received humane care in compliance with the "Principles of Laboratory Animal Care" formulated by the National Society for Medical Research and the "Guide for the Care and Use of Laboratory Animals" published by the National Institutes of Health (NIH publication No. 86-23, revised 1985).

Assessment of lung function. After 18 hours of storage at $4^{\circ} \mathrm{C}$ the lung-heart block was suspended by a force transducer in a warm, humidified tissue chamber. Ventilation was reestablished with a $95 \%$ oxygen $/ 5 \%$ carbon dioxide gas mixture at a tidal volume of $12 \mathrm{ml} / \mathrm{kg}$ and a respiratory rate of $20 \mathrm{breaths} / \mathrm{min}$. The lungs were reperfused with homologous fresh whole venous blood from a main reservoir. A second venous blood reservoir was used to determine single-pass oxygenation at 10,20 , and 30 minutes after initiation of reperfusion. Blood was harvested from a single rabbit for each experiment. The inflow and outflow cannulas were then connected to the blood-primed perfusion circuit with care taken to avoid the introduction of air. The perfusion circuit (Kent Scientific Corporation) was designed to recirculate $150 \mathrm{ml}$ of 


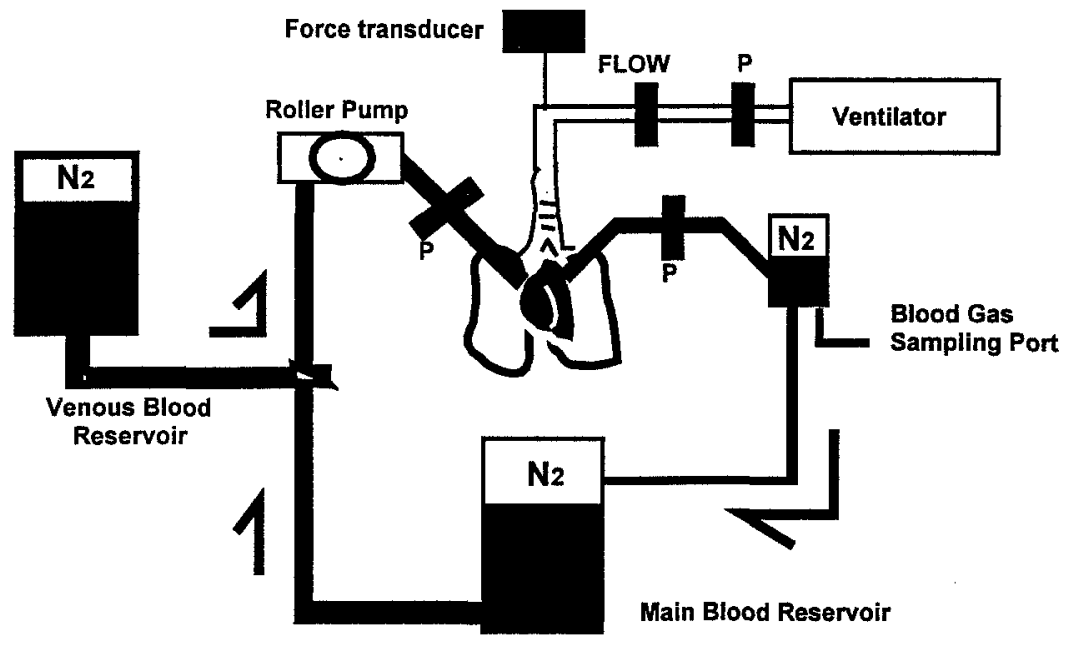

Fig. 1. Schematic diagram of experimental model.

warmed blood through a $270 \mu \mathrm{m}$ blood filter (No. 2C7600, Baxter, Deerfield, III.) with a roller pump (No. 7521-40, Cole Palmer Instrument Company, Chicago, Ill.) at a rate of $60 \mathrm{ml} / \mathrm{min}$ (Fig. 1). A $270 \mu \mathrm{m}$ blood filter was chosen so as not to affect leukocyte or platelet counts.

Continuous recording of pulmonary artery pressure (PAP), left atrial pressure, lung weight, airway flow, and airway pressure was facilitated by use of a dynamic data acquisition program (Workbench PC, Strawberry Tree, Inc., Sunnydale, Calif.) run on a PC computer (No. 470A, Compaq Prolinea, Houston, Tex.). This program automatically calculated and displayed pulmonary vascular resistance (PVR), tidal volume, and dynamic airway compliance. The left atrial pressure was maintained within the physiologic range ( 4 to $8 \mathrm{~mm} \mathrm{Hg}$ ) by adjusting the height of a small outflow reservoir in the circuit. Pulmonary venous blood samples were collected for blood gas analysis (Corning $178 \mathrm{pH} /$ blood gas analyzer, Medfield, Mass.) at 10,20 , and 30 minutes after the start of reperfusion. At each sampling interval inflow from the main reservoir was interrupted and the circuit was filled with venous blood from the second inflow reservoir. Thirty milliliters of venous blood was passed through the pulmonary vasculature at each interval to ensure accurate measurement of pulmonary venous oxygen content. Oxygen contact with exposed blood surfaces inside the reservoir containers was minimized by the continuous infusion of $100 \%$ nitrogen. After 30 minutes of reperfusion, specimens of lung tissue were acquired for weight analysis. Wet-to-dry ratios were calculated after passive desiccation at room temperature to a stable dry weight.

Experimental protocol. All lungs were stored inflated at $4^{\circ} \mathrm{C}$ for 18 hours after injection of $30 \mu \mathrm{g} \mathrm{PGE}_{1}$ and single-flush preservation with $50 \mathrm{ml} / \mathrm{kg}$ of solution. Three experimental groups were defined on the basis of the preservation solution the lungs were randomized to receive (Table I). The first group of animals (EC group) received Euro-Collins solution $(N=8)$. The second group received low-potassium dextran (LPD) solution $(N=8)$. The third group received a flush solution composed of low-potassium
Table I. Experimental protocol and flush compositions

\begin{tabular}{lccc}
\hline \multicolumn{1}{c}{ Component } & $\begin{array}{c}\text { Euro-Collins } \\
(n=8)\end{array}$ & $\begin{array}{c}\text { LPD } \\
(n=8)\end{array}$ & $\begin{array}{c}B L P D \\
(n=7)\end{array}$ \\
\hline $\mathrm{Na}^{+}(\mathrm{mmol} / \mathrm{L})$ & 10 & 71.5 & 98.5 \\
$\mathrm{~K}^{+}(\mathrm{mmol} / \mathrm{L})$ & 115 & 2.2 & 3.3 \\
$\mathrm{Cl}^{-}(\mathrm{mmol} / \mathrm{L})$ & 15 & 60 & 80 \\
$\mathrm{HCO}_{3}{ }^{-}(\mathrm{mmol} / \mathrm{L})$ & 10 & - & - \\
$\mathrm{HPO}_{4}{ }^{2-}(\mathrm{mmol} / \mathrm{L})$ & 42.5 & 14 & 14 \\
$\mathrm{H}_{2} \mathrm{PO}_{4}{ }^{-}(\mathrm{mmol} / \mathrm{L})$ & 15 & - & - \\
$\mathrm{Mg}^{2+}(\mathrm{mmol} / \mathrm{L})$ & - & 2.0 & 2.0 \\
$\mathrm{Ca}^{2+}(\mathrm{mg} / \mathrm{dl})$ & - & 1.5 & 3.5 \\
$\left.\mathrm{Lactate}^{2} \mathrm{mmol} / \mathrm{L}\right)$ & - & 15.4 & 15.4 \\
Dextran $(\mathrm{gm} / \mathrm{L})$ & - & 25 & 25 \\
Dextrose $(\mathrm{gm} / \mathrm{L})$ & 35 & 15 & 15 \\
Donor blood $(\%)$ & - & - & 20 \\
$\mathrm{pH}\left(4^{\circ} \mathrm{C}\right)$ & 7.25 & $7.3-7.5$ & $7.3-7.5$ \\
\hline
\end{tabular}

dextran solution with a $20 \%$ addition of autologous heparinized whole venous blood (BLPD solution) $(N=7)$. All lungs were reperfused at a physiologic flow rate of $60 \mathrm{ml} / \mathrm{min}$ for 30 minutes. Data were recorded every 15 seconds and analyzed at the end of the 30-minute reperfusion period. Oxygenation data were obtained and analyzed at 10-minute intervals. All values are expressed as the mean plus or minus the standard error of the mean. Statistical analysis was done by analysis of variance to compare the experimental groups. Differences were considered statistically significant if the $p$ value was less than 0.05 .

\section{Results}

Pulmonary function was assessed during reperfusion by the following parameters: PAP, PVR, dynamic lung compliance, and oxygenation capacity. In our model, we defined oxygenation capacity as the ability of the lungs to oxygenate venous blood 
Table II. Parameters of lung function after 30 minutes of reperfusion

\begin{tabular}{lccccc}
\hline Group & $P A P$ & $\begin{array}{c}\text { PVR } \\
(\mathrm{mm} \mathrm{Hg})\end{array}$ & $\begin{array}{c}\text { Wet/dry } \\
\left(\text { dynes } \cdot \mathrm{sec}^{*} \mathrm{~cm}^{-5}\right)\end{array}$ & $\begin{array}{c}\text { V-A } \mathrm{O}_{2} \\
(\% \Delta)\end{array}$ & $\begin{array}{c}\text { ratio } \\
(\mathrm{mm} \mathrm{Hg})\end{array}$ \\
\hline EC $(\mathrm{n}=8)$ & $40.8 \pm 2.2^{*}$ & $46.0 \pm 3.1 \dagger$ & $-21.9 \pm 4.7 \ddagger$ & $7.4 \pm 0.3 \S$ & $37.2 \pm 4.6 \|$ \\
LPD $(\mathrm{n}=8)$ & $28.9 \pm 2.4$ & $29.0 \pm 4.2$ & $1.8 \pm 3.3$ & $5.6 \pm 0.1$ & $296.3 \pm 54.6$ \\
BLPD $(\mathrm{n}=7)$ & $28.3 \pm 1.5$ & $28.8 \pm 2.3$ & $1.4 \pm 6.2$ & $5.7 \pm 0.3$ & $290.2 \pm 66.4$ \\
\hline
\end{tabular}

Values demonstrate superior preservation with extracellular solutions (LPD and BLPD) as compared with preservation with Euro-Collins solution. $V-A O_{3}$ venous-arterial oxygen gradient.

${ }^{*} p=0.0003$ versus LPD and BLPD groups.

$\dagger p=0.0005$ versus LPD and BLPD groups.

$\ddagger p=0.002$ versus LPD and BLPD groups.

$\S p=0.0001$ versus LPD and BLPD groups.

$\| p=0.001$ versus $\mathrm{LPD}$ and BLPD groups.

during a single pass from the pulmonary artery to the left atrium. It is reported as a venous-arterial gradient to normalize for gradual decreases that occur in the venous blood oxygen tension during the course of the experiment. At the end of the 30minute reperfusion period tissue samples were obtained for determination of wet-to-dry ratios.

Lungs preserved with LPD and BLPD solutions demonstrated improvement in all parameters of pulmonary function when compared with results in the EC group after 30 minutes of reperfusion (Table II). The EC group demonstrated a significant elevation in PAP when compared with values in the LPD and BLPD groups $(40.8 \pm 2.2 \mathrm{~mm} \mathrm{Hg}$ vs $28.9 \pm 2.4$ $\mathrm{mm} \mathrm{Hg}$ and $28.3 \pm 1.5 \mathrm{~mm} \mathrm{Hg}$, respectively; $p<$ $0.001)$. Similarly, PVR was elevated $(46.0 \pm 3.1 \times$ $10^{3}$ dynes $\cdot \mathrm{sec} \cdot \mathrm{cm}^{-5}$ vs $29.0 \pm 4.2 \times 10^{3}$ dynes $\cdot \mathrm{sec} \cdot \mathrm{cm}^{-5}$ and $28.8 \pm 2.3 \times 10^{3}$ dynes $\cdot \mathrm{sec} \cdot \mathrm{cm}^{-5}$, respectively; $p<0.001$ ). These values are elevated because of the perfusion circuit; however, absolute differences between groups are caused by changes in the pulmonary vasculature as a result of preservation. The EC group revealed a greater drop in compliance when compared with the LPD and BLPD groups $(-21.9 \% \pm 4.7 \%$ vs $1.8 \% \pm$ $3.3 \%$ and $1.4 \% \pm 6.2 \%$, respectively; $p=0.002$ ). Oxygenation capacity in both groups that received extracellular-type solutions (LPD and BLPD groups) was significantly improved as compared with that in the EC group $(296.3 \pm 54.6 \mathrm{~mm} \mathrm{Hg}$ and $290.2 \pm 66.4 \mathrm{~mm} \mathrm{Hg}$, respectively, vs $37.2 \pm 4.6 \mathrm{~mm}$ $\mathrm{Hg} ; p=0.001$ ) (Fig. 2). In addition, LPD- and BLPD-preserved lungs had less edema formation at the end of the reperfusion period when compared with that in the EC group (wet-to-dry ratios: $5.6 \pm$ 0.1 and $5.7 \pm 0.3$, respectively, vs $7.4 \pm 0.3 ; p=$ $0.0001)$.

When the LPD group was compared with the
BLPD group, no significant differences in pulmonary function were demonstrated in any of the parameters measured.

\section{Discussion}

Despite recent advances in virtually all aspects of lung transplantation, reliable extended graft preservation has not been achieved. Even with limited storage periods of less than 6 hours, varying degrees of reperfusion injury are encountered frequently and at times even result in graft failure. This injury is often attributable to, or exacerbated by, inadequate graft preservation. Single-flush perfusion of the pulmonary vasculature is a widely accepted method of lung preservation because of its simple application, lack of cardiac effects, and acceptable results. However, variable results have been reported depending on the type of preservation solution used with this technique..$^{6-18}$

Previously, we have demonstrated that a lowpotassium solution improves lung function whereas Euro-Collins solution exacerbates lung injury in the setting of high-flow reperfusion. ${ }^{19,20}$ These studies were not designed to specifically evaluate the preservation characteristics of these solutions and were therefore done after a relatively short storage period of 4 hours to minimize the effects of ischemia. In the current study we used an isolated, ventilated/bloodperfused rabbit lung model to directly compare three lung preservation solutions and determine whether extracellular solutions provide superior protection of the lung after 18 hours of cold ischemia. Euro-Collins solution was chosen as a representative intracellular solution inasmuch as it is commonly used in clinical practice.

In this experiment, lungs preserved with extracellular-type solutions, LPD and BLPD, demonstrated improved function as compared with function in 
lungs preserved with Euro-Collins solution. This improvement was seen in all parameters of lung function; most dramatically in the lung's ability to oxygenate venous blood. Oxygenation during reperfusion remains the single most important indicator of adequate pulmonary preservation, and these differences between extracellular and intracellular solutions suggest both harmful effects of Euro-Collins solution and beneficial effects of LPD and BLPD solutions.

Euro-Collins solution is an intracellular-type solution initially designed to protect renal parenchymal cells from inappropriate cation exchange and cell edema during ischemia. ${ }^{21}$ However, the lung is physiologically and anatomically distinct from the kidney, therefore renal preservation strategies may not be optimal for a pulmonary graft. The lung is unique in its ability to maintain aerobic metabolism during ischemia as it uses oxygen stored within the alveoli. $^{22,23}$ Therefore the lung is relatively tolerant of ischemia. Euro-Collins solution, which stabilizes cation flux and prevents cellular edema during the ischemic interval, is poorly designed to protect an organ whose morphologic structure minimizes the effects of ischemia, provided it is stored in the inflated state. By clamping the trachea at end inspiration before storage, oxygen is maintained in the alveolar space to allow for ongoing metabolism.

In addition, the high potassium content of EuroCollins solution, included to minimize cation flux and preserve energy stores, has profound effects on the pulmonary vasculature. Potassium-induced vasoconstriction not only causes increased PVR during early reperfusion but also results in nonhomogeneous flushing of the graft and poorly preserved areas of parenchyma. ${ }^{11,20,24,25}$ High potassium contents also have a direct effect on endothelial cell function ${ }^{26}$ and have been shown to be injurious to type II pneumocytes in cell culture. ${ }^{27}$ Our findings in this study corroborate the detrimental effects of potassium on the pulmonary vasculature. The EC group had significant elevations in PAP and PVR even after 30 minutes of reperfusion, which suggests endothelial cell dysfunction or injury. $\mathrm{PGE}_{1}$ has been used to overcome the potassium-induced vasoconstriction caused by intracellular-type solutions and may also provide additional preservation benefits. Whether PGE $_{1}$ is effective in overcoming this vasoconstriction and improving pulmonary function is controversial. ${ }^{13,24}$ Several investigators have directly compared low-potassium extracellular-type solutions with intracellular-type solutions ${ }^{11,18,28}$;

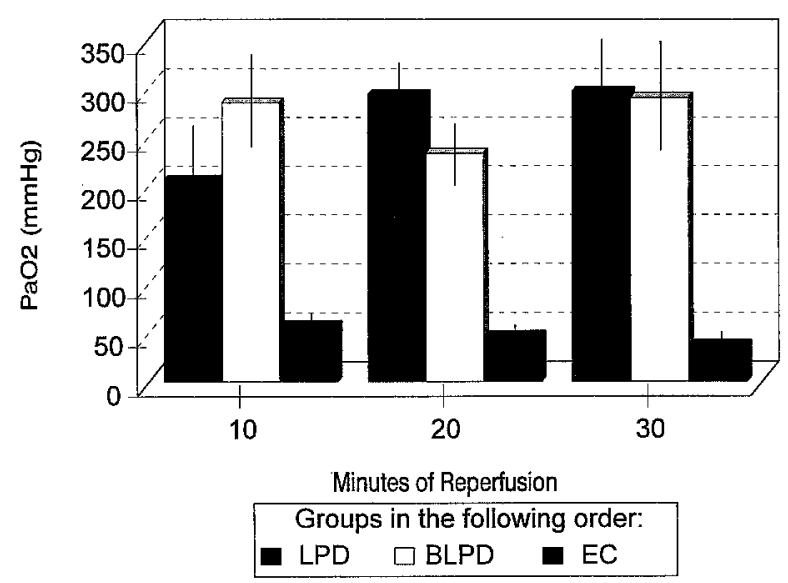

Fig. 2. Pulmonary venous-arterial oxygen gradient at 10 , 20 , and 30 minutes of reperfusion. Both LPD and BLPD solutions demonstrated significant improvement in oxygenation over that in lungs preserved with Euro-Collins solution. $\mathrm{PaO}_{2}$, Arterial oxygen tension.

however, these studies did not use $\mathrm{PGE}_{1}$ before flushing of the graft. In this study we have demonstrated that lung function after preservation with Euro-Collins solution is inferior to that with both LPD and BLPD solution, despite the use of $\mathrm{PGE}_{1}$. A potential limitation of this model may be the inherent sensitivity of the vasculature of Rodentia to high concentrations of potassium, resulting in a more severe injury. However, the human pulmonary vasculature also remains sensitive to potassium at comparable concentrations ${ }^{29}$ and may be subject to these detrimental effects.

The beneficial effects of the extracellular-type solutions investigated (LPD and BLPD) may not only be a result of the low potassium contents, but also of the addition of dextran. Belzer and Southard ${ }^{28}$ described impermeants as key components of successful cold storage solutions. In the lung, where interstitial edema impairs its most important function of gas exchange, the role of impermeants may be even more significant. Additional benefits of dextran may be a result of enhanced flow characteristics in the capillaries, antithrombotic properties via effects on the endothelium and platelets, and its potential free-radical scavenging abilities. ${ }^{30}$ Significantly improved wet-to-dry ratios were seen with the use of dextran in our model, which supports the importance of including an impermeant in lung preservation solutions.

In this model of 18-hour ischemia we were unable to demonstrate any advantage with the addition of 
whole heparinized blood to the preservation solution. The theoretic benefits of including blood in organ preservation solutions include provision of substrates for continued metabolism and intact buffering mechanisms. ${ }^{16}$ The inclusion of blood also provides additional impermeants. We were unable to reveal any significant differences between the LPD and BLPD solutions in this model. Perhaps a longer period of ischemia would have elucidated any advantages that blood may confer in pulmonary preservation solutions. The detrimental effects of leukocytes on lung function after preservation have been demonstrated, ${ }^{1-4}$ and perhaps the addition of leukocyte-free blood would be more appropriate.

In conclusion, lung preservation with extracellular-type solutions, LPD and BLPD, resulted in superior pulmonary function as compared with the use of Euro-Collins solution in this rabbit lung model. We believe the ideal solution for lung preservation will place less emphasis on parenchymal preservation and focus instead on protecting the endothelium from the detrimental events that occur during reperfusion. Improved preservation will likely result in a decreased prevalence and severity of reperfusion injury after lung transplantation.

We acknowledge the technical advice of Anthony J. Herring.

\section{REFERENCES}

1. Buchanan SA, Mauney MC, DeLima NF, et al. Enhanced isolated lung function after ischemia with anti-intercellular adhesion molecule antibody. J Thorac Cardiovasc Surg 1996; 111:941-7.

2. Pillai R, Bando K, Schueler S, Zebley M, Reitz BA, Baumgartner WA. Leukocyte depletion results in excellent heartlung function after 12 hours of storage. Ann Thorac Surg 1990;50:211-4.

3. Schueler S, De Valeria PA, Hatanaka M, et al. Successful twenty-four hour lung preservation with donor core cooling and leukocyte depletion in an orthotopic double lung transplantation model. J Thorac Cardiovasc Surg 1992;104:73-82.

4. Binns OAR, DeLima NF, Buchanan SA, et al. Neutrophil endopeptidase inhibitor improves pulmonary function during reperfusion after eighteen-hour preservation. J Thorac Cardiovase Surg 1996;112:607-13.

5. Wallwork J, Jones K, Cavarocchi N, Hakim M, Higenbottam $\mathrm{T}$. Distant procurement of organs for clinical heart-lung transplantation using a single-flush technique. Transplantation 1987;44:654-8.

6. Sundaresan S, Lima O, Date H, et al. Lung preservation with low-potassium dextran flush in a primate bilateral transplant model. Ann Thorac Surg 1993;56:1129-35.

7. Steen S, Kimblad PO, Sjöberg T, Lindberg L, Ingemansson R, Massa G. Safe lung preservation for twenty-four hours with Perfadex. Ann Thorac Surg 1994;57:450-7.

8. Date H, Izumi S, Miyade Y, Andou A, Shimizu N, Teramoto
S. Successful canine bilateral single lung transplantation after 24-hour lung preservation. Ann Thorac Surg 1995;59:336-41.

9. Wisser W, Ringl H, Wekerle T, Wolner E, Klepetko W. A new flush solution for extended lung preservation. J Heart Lung Transplant 1995;14:289-95.

10. Keshavjee SH, Yamazaki F, Cardoso PF, et al. A method for safe twelve-hour pulmonary preservation. J Thorac Cardiovasc Surg 1989;98:529-34.

11. Yamazaki F, Yokomise H, Keshavjee SH, et al. The superiority of an extracellular fluid solution over Euro-Collins' solution for pulmonary preservation. Transplantation 1990; 49:690-4.

12. Fujimara S, Kondo T, Handa M, et al. Successful 24-hour preservation of canine lung transplants using modified extracellular fluid [abstract]. Transplant Proc 1985;17:1466.

13. Puskas JD, Cardoso PFG, Mayer E, Shi S, Slutsky AS, Patterson GA. Equivalent eighteen-hour lung preservation with low-potassium dextran or Euro-Collins solution after prostaglandin $E_{1}$ infusion. J Thorac Cardiovasc Surg 1992; 104:83-9.

14. Baldwin JC, Frist WH, Starkey TD, et al. Distant graft procurement for combined heart and lung transplantation using pulmonary artery flush and simple topical hypothermia for graft preservation. Ann Thorac Surg 1987;43:670-3.

15. Haverich A, Aziz S, Scott WC, Jamieson SW, Shumway NE. Improved lung preservation using Euro-Collins solution for flush perfusion. J Thorac Cardiovasc Surg 1986;34:368-78.

16. Modry DL, Walpoth BW, Cohen RG, et al. Heart-lung preservation in the dog followed by lung transplantation. J Heart Transplant 1983;2:287-98.

17. Jones KD, Cavarocchi N, Hakim M, Cory-Pearce R, English TAH, Wallwork J. A single flush technique for successful distant organ procurement in heart-lung transplantation [Abstract]. J Heart Transplant 1985;4:614.

18. Xiong L, Mazmanian M, Chapelier AR, et al. Lung preservation with Euro-Collins, University of Wisconsin, Wallwork, and low-potassium dextran solutions. Ann Thorac Surg 1994; 58:845-50.

19. DeLima NF, Binns OAR, Buchanan SA, et al. Low-potassium solution for lung preservation in the setting of high-flow reperfusion. Ann Thorac Surg 1996;61:973-6.

20. DeLima NF, Binns OAR, Buchanan SA, et al. Euro-Collins solution exacerbates lung injury in the setting of high-flow reperfusion. J Thorac Cardiovasc Surg 1996;112:111-6.

21. Collins GM. Flush preservation. In: Pegg DE, Jacobsen IA, Halasz NA, eds. Organ preservation: basic and applied aspects. Lancaster, England:MTP Press, 1982:167.

22. Weder W, Harper BD, Shimokawa S, et al. Influence of intraalveolar oxygen concentration on lung preservation in a rabbit model. J Thorac Cardiovasc Surg 1991;101:1037-43.

23. Date $\mathrm{H}$, Lima $\mathrm{O}$, Matsumura A, Tsuji $\mathrm{H}$, d'Avignon DA, Cooper JD. In a canine model, lung preservation at $10^{\circ} \mathrm{C}$ is superior to that at $4^{\circ} \mathrm{C}$ : a comparison of two preservation temperatures on lung function and on adenosine triphosphate level measured by phosphorus 31-nuclear magnetic resonance. J Thorac Cardiovasc Surg 1992;103:773-80.

24. Kimblad PO, Sjöberg T, Massa G, Solem J-O, Steen S. High potassium contents in organ preservation solutions cause strong pulmonary vasoconstriction. Ann Thorac Surg 1991; 52:523-8.

25. Sasaki S, McCully JD, Alessandrini F, LoCicero J. Impact of 
initial flush potassium concentration on the adequacy of lung preservation. J Thorac Cardiovasc Surg 1995;109:1090-6.

26. Chan BBK, Kron IL, Flanagan TL, Kern JA, Hobson CE, Tribble CG. Impairment of vascular endothelial function by high-potassium storage solutions. Ann Thorac Surg 1993;55: 940-5.

27. Hachida M, Hoon DSB, Morton DL. A comparison of solutions for lung preservation using pulmonary alveolar type II cell viability. Ann Thorac Surg 1988;45:643-6.

28. Belzer FO, Southard JH. Principles of solid-organ preservation by cold storage. Transplantation 1988;45:673-6.

29. Mikkelsen EO, Sakr AMR, Jespersen LT. Effects of nifedipine on contractile responses to potassium, histamine, and 5-hydroxytryptamine in isolated human pulmonary vessels. J Cardiovasc Pharmacol 1983;5:317-20.

30. Keshavjee SH, Yamazaki F, Yokomise H, et al. The role of dextran 40 and potassium in extended hypothermic lung preservation for transplantation. J Thorac Cardiovasc Surg 1992;103:314-25.

\section{Discussion}

Dr. Larry R. Kaiser (Philadelphia, Pa.). Could some of the advantage from the blood-based solution possibly be due to a variation in the distribution? Perhaps the increased viscosity of the blood-based solution might contribute to a poorer distribution. Is there any way to look at that?

Dr. Binns. We did not investigate that in any way. Methods have been reported in which one could use labeled albumin or some other technique to track where the perfusate is going throughout the lung, but we did not look at that at all.

Dr. G. Alexander Patterson (St. Louis, Mo.). We published some work quite a while ago that said LPD solution was a superior preservation solution in a variety of models, and then it happened that we determined in a group of canine experiments and a group of canine reports that so long as the donor lung was vasodilated or pretreated by $\mathrm{PGE}_{1}$, prostacyclin, high-volume ventilation, or any method that achieved satisfactory vasodilatation, that any difference in LPD solution was eliminated. This study was conducted in rabbits, correct? I think it is impossible to get Euro-Collins solution or an intracellular solution into a rabbit or rodent lung, whereas it is easy to flush them with an extracellular solution. I would appreciate your comments on how much of these results you think are species dependent.

Dr. Binns. We have to be cautious any time we extrapolate our results in small animal studies to the human situation, or even to larger animal studies for that matter. The pulmonary vasculature of the rabbit is definitely responsive to potassium; however, the human vasculature also remains responsive to potassium at even low concentrations of $20 \mathrm{mmol} / \mathrm{L}$. I think that some of the responses we see are definitely occurring in the human vasculature. We may not be able to demonstrate the response quite as dramatically because of the larger capacitance vascular bed that we are perfusing. In any case, we have to be cautious when applying these findings in experimental models to human situations. A randomized, prospective clinical study is needed to clarify this issue.

Dr. Shaf Keshavjee (Toronto, Ontario, Canada). Along the same lines, I think that the improvement in lung preservation related to LPD versus Euro-Collins solution in this setting was much greater. Even though the buffering effect of blood has been shown to be beneficial, it is a smaller effect, and I wonder whether with $50 \mathrm{ml} / \mathrm{kg}$ of flush solution there was still blood in the lungs and therefore there was a buffering effect of blood even in the LPD group compared with the blood plus LPD group?

Dr. Binns. The only comment I can make is that the effluent from the venous outflow cannulas after flushing the lungs was clear, but we did not actually measure the hematocrit value.

\section{Bound volumes available to subscribers}

Bound volumes of The Journal of Thoracic and Cardiovascular Surgery are available to subscribers (only) for the 1996 issues from the Publisher, at a cost of $\$ 100.50$ for domestic, $\$ 128.94$ for Canadian, and $\$ 120.50$ for international subscribers for Vol. 111 (January-June) and Vol. 112 (July-December). Shipping charges are included. Each bound volume contains a subject and author index and all advertising is removed. Copies are shipped within 60 days after publication of the last issue of the volume. The binding is durable buckram with the Journal name, volume number, and year stamped in gold on the spine. Payment must accompany all orders. Contact Mosby-Year Book, Inc., Subscription Services, 11830 Westline Industrial Drive, St. Louis, Missouri 63146-3318, USA; phone $800-453-4351$ or 314-453-4351.

Subscriptions must be in force to qualify. Bound volumes are not available in place of a regular Journal subseription. 